\title{
GLOBALIZAÇÃO, TRABALHO E DOCÊNCIA: CONSTATAÇÕES E POSSIBILIDADES
}

\author{
Afonso Celso Scocuglia \\ (UFPB/CNPq) \\ afonso.scocuglia@pq.cnpq.br
}

\section{RESUMO}

Este artigo analisa alguns impactos da globalização hegemônica no mundo do trabalho e da identidade docentes, tomando o caso brasileiro como referência. Buscamos compreender o cenário da precarização do trabalho, as identidades dilaceradas dos trabalhadores, as possíveis alternativas destes processos e os novos protagonistas da sociedade civil. Nesse cenário, as possibilidades de reinvenções do trabalho e da identidade docentes constituem nossos focos. Dividimos nossa argumentação em partes ligadas que se retro-alimentam. Na primeira parte, argumentamos sobre a precarização do trabalho no contexto neoliberal e globalizado, procurando alternativas deste quadro por meio do cooperativismo e dos diversos protagonismos da sociedade civil. Na segunda parte, tentamos visualizar os rebatimentos desse contexto na precarização e na identidade do trabalho docente, bem como as possíveis reinvenções das práticas pedagógicas dos/as professores/as. Nas considerações finais, afirmamos os caminhos complexus da reconstrução da identidade educativa e docente, utilizando a conceituação sobre a ação dialógica, a consciência crítica, sobre a história como possibilidade de atuação do/a educador/a enquanto trabalhador e intelectual.

Palavras-chave: globalização, precarização do trabalho, protagonismo social, reinvenção docente, história como possibilidade e consciência crítica.

\section{GLOBALIZATION, LABOR AND TEACHING: FINDINGS AND POSSIBILITIES}

\begin{abstract}
This article examines some impacts of globalization on the hegemonic globalization of work and the identity of teachers, taking the Brazilian case as a reference. We seek to clearly understand the precariousness of work, the identities of workers torn, the possible alternatives of these processes and new civil society actors. In this scenario, the possibilities for reinvention of work and the identity of teachers are our focus. We divide our argument into parts that are connected back-feed. In the first part, we argue about the precariousness of work in neoliberal and globalized, looking for alternatives in this table through the cooperatives and the various civil society actors. In the second part, we try to see the reverberations of that connection and the precariousness of identity in teaching, as well as the possible reinvention of the teaching practices of the teacher. In the final consideration, we affirm the ways complexus reconstruction of identity and teacher education, using the concept of the dialogical action, critical conscientization, about the history and the possibility of action of the educator (worker and intellectual).

Keywords: globalization, precarious employment, social role, reinventing teaching, history as a possibility and critical conscientization.
\end{abstract}




\section{Parte I - Precarização do trabalho, cooperativismo e protagonismo social.}

\section{I.1 - O mundo do trabalho precarizado e a classe-que-vive-do-trabalho}

O mundo do trabalho foi um dos mais impactados pela globalização hegemônica ${ }^{i}$ do capital. O edifício trabalhista construído pela Revolução Industrial com os lastros taylorista e fordista, foi amplamente remodelado nas últimas décadas do século XX. A precarização do trabalho, o subemprego e o desemprego, concomitante aos avanços das formas de exploração, deixaram transparentes seu atual estágio, mas não nos autorizam a dar crédito às teses sobre o "fim do trabalho" e da própria classe trabalhadora. Ao contrário, mostra-nos a necessidade de melhor compreender a reestruturação da classeque-vive-do-trabalho (Antunes, 1995 e 1999).

A diversidade e a fragmentação social dos que vivem da venda do seu trabalho pode ser evidenciada de várias formas. Em primeiro lugar, houve uma notória e volumosa redução dos contingentes dos trabalhadores industriais herdeiros do taylorismo e do fordismo, marcada pela reestruturação capitalista que desregulamentou e desestabilizou o mundo do trabalho formal, tornou flexível e desconcentrou o espaço do trabalho e introduziu a telemática como seu principal veículo. Esta reestruturação também implicou o aumento de uma nova tipologia de trabalho precarizado, ou seja, a terceirização, a subcontratação e os contratos de tempos parciais. Estes postos de trabalho cada vez mais são ocupados pelos desempregados da fase capitalista anterior e caracterizam o crescimento da informalidade que identifica parte significativa dos trabalhadores brasileiros na atualidade. Com efeito, o refluxo da industrialização implicou o trabalho parcial, temporário, terceirizado, informal, ou numa só palavra, o trabalho precarizado (Antunes e Alves, 2004). Uma das consequências mais visíveis diz respeito ao trabalho feminino, cada vez mais presente na tipificação do trabalho precário e desregulado e, pior, como remuneração mais baixa que o masculino, demonstrando uma "nova divisão sexual do trabalho" (Hirata, 2002) na qual são destinados às mulheres os menores níveis de qualificação e de remuneração.

$\mathrm{O}$ crescimento dos serviços também deixa à mostra que as mudanças no mundo do trabalho afetaram este setor por meio da crescente racionalidade do capitalismo lastreado na expansão dos mercados financeiros. Segundo Antunes e Alves (2004, p.338), na "interrelação crescente entre mundo produtivo e setor de serviços (...), várias atividades no setor de serviços, anteriormente consideradas improdutivas, tornaram-se diretamente produtivas, subordinadas à lógica exclusiva da racionalidade econômica e da valorização do capital". Isto se mostra particularmente significativo entre os assalariados médios dos serviços e, como fator positivo, tende a aumentar os contingentes de sindicalizados da classe-quevive-do-trabalho.

Também é notória a exclusão dos jovens do primeiro emprego, que tendem ao trabalho precário e ao desemprego estrutural. Ao mesmo tempo, ocorre a exclusão dos que são considerados velhos para o capitalismo, que têm imensas dificuldades de retorno ao trabalho formal e que, inevitavelmente, caem na informalidade, no desemprego permanente e/ou no voluntarismo. Para estes últimos, a experiência de trabalho fordista não serve à polivalência e à multifuncionalidade exigidas pelo toyotismo. Soma-se a essas exclusões a incorporação ilegal de crianças ao mercado de trabalho brasileiro.

Chama também a atenção uma espécie de mistificação e escamoteamento das questões estruturais do novo mundo do trabalho na era da globalização: as formas alternativas de ocupação do que é denominado de Terceiro Setor. Este espaço vem incorporando excluídos do trabalho formal (o que pode se considerar uma solução) e que 
começam a desenvolver atividades não mercantis, mas não se pode entendê-lo como alternativa estrutural à exclusão, parecendo mais uma saída funcional do próprio sistema que não consegue resolver nem a ausência do emprego, nem a precarização do trabalho no Brasil.

Dois outros registros servem para configurar a nova e ampliada classe trabalhadora: os trabalhadores produtivos domésticos da telemática que crescem mundialmente e misturam sua atuação local/regional/nacional com a internacional. Este último segmento atesta as novas fronteiras globalizadas do mundo do trabalho e, assim como os outros condicionamentos que submetem os trabalhadores e precarizam o trabalho, amplia a necessidade da organização local/global dos/as trabalhadores/as para se contrapor aos desígnios da globalização excludente.

Ademais, temos "o proletariado rural, que vende a sua força de trabalho para o capital, de que são exemplos os assalariados das regiões agroindustriais, e incorpora também o proletariado precarizado, o proletariado moderno, fabril e de serviços, part-time, que se caracteriza pelo vínculo de trabalho temporário, pelo trabalho precarizado, em expansão na totalidade do mundo produtivo" (Antunes e Alves, 2004, p.341). Além dos trabalhadores desempregados. Por esta razão,

\footnotetext{
Compreender, a classe-que-vive-do-trabalho, a classe trabalhadora, hoje, de modo ampliado, implica entender este conjunto de seres sociais que vivem da venda da sua força de trabalho, que são assalariados e desprovidos do mundo da produção. Como todo trabalho produtivo é assalariado, mas nem todo trabalhador assalariado é produtivo, uma noção contemporânea de classe trabalhadora deve incorporar a totalidade dos (as) trabalhadores (as) assalariados (as). (...) Ela tem, portanto, uma conformação mais fragmentada, mais heterogênea, mais complexificada. Que somente pode ser apreendida se partirmos de uma noção ampliada de trabalho. E apresentar essa processualidade multiforme é muito diferente do que afirmar o fim do trabalho ou até mesmo o fim da classe trabalhadora. (ibidem, p.341)
}

Este novo mundo trabalho precarizado, constituído por uma classe trabalhadora complexificada, produz um sujeito que, cada vez mais, subordina-se à ideologia da qualidade total, internaliza a possibilidade da exclusão e a "necessidade" crescente de utilização de todo o tempo disponível para buscar as "competências" e as "habilidades" exigidas pelo mercado. Como os postos de trabalho decrescem, a seletividade e a exclusão são regras fixas, o desemprego, o subemprego e o trabalho precarizado dão a tônica. Temos tudo para encontrar um volumoso número de pessoas excluídas dos setores produtivos e marcadas pela desumanização, pelo cotidiano sem sentido, pela desagregação social, por todas as formas de violência e todas as possibilidades da explosão societária. E, certamente, por uma identidade pessoal e profissional dilacerada.

\section{I.2 - Cooperativismo e economia solidária}

Uma das tentativas de respostas ao avanço da globalização hegemônica e às conseqüentes mudanças no mundo do trabalho, colocadas anteriormente, tem sido praticada pelos defensores do cooperativismo e da economia solidária. Estes são pensados enquanto contrapontos (sócio-econômicos e político-pedagógicos) à concentração e à exploração do que é produzido pela classe-que-vive-do-trabalho e contrários às várias 
formas de exclusão patrocinadas pela globalização e pelo neoliberalismo dominantes. Para Schneider (2002),

As cooperativas são uma das respostas para os problemas impostos pela globalização. Por um lado, geram empregos, por outro, são um contrapeso à concentração de riquezas. E se as cooperativas, em nome do princípio da integração buscam a concentração, no cooperativismo, tal concentração não representa a exclusão, como no modelo capitalista. É uma concentração de centenas e milhares de associados produtores rurais, artesanais, poupadores, consumidores, prestadores de serviços. A integração/concentração de empresas que representam milhões de coproprietários cooperativados é um processo que reforça as condições para uma melhor distribuição de renda e das oportunidades. (p.2)

Segundo seus defensores, as propostas e as ações do cooperativismo passam pela luta pelo pleno emprego, pela distribuição eqüitativa da renda gerada pelo trabalho, pela segurança alimentar, pela conservação ambiental e pelo desenvolvimento local e sustentável e pelos direitos civis, sociais e políticos inerentes às conquistas da cidadania e da justiça social. Por outro lado, acreditam que quanto mais globais são os problemas, mais locais são suas soluções e que é necessário pensar globalmente e agir localmente. Neste sentido, haveria uma maior homogeneidade cultural e sócio-econômica no local que seria um contraponto à fragmentação e à própria precarização do trabalho. Com a proximidade das pessoas e dos grupos, haveria um maior comprometimento coletivo pela resolução de problemas comuns e as formas de organização e as ações políticas fluiriam com maior facilidade. Neste caminho, as redes de solidariedade seriam viáveis e exequiíveis.

$\mathrm{O}$ que estaria em jogo é a possibilidade concreta de reconstruir o potencial local no contexto da globalização hegemônica. E, certamente, essa é uma idéia convergente com o que Boaventura de Sousa Santos caracterizou como "cosmopolitismo" enquanto possibilidade da globalização contra-hegemônica (ver p.4-5). As redes locais/regionais e nacionais seriam, deste prisma, ações "de-baixo-para-cima" fundamentais e contrapontos à globalização hegemônica e à fragmentação do trabalho da prática neoliberal. Schneider (2002) argumenta que possivelmente "as redes de cooperativas (COREDES), as instâncias locais do Orçamento Participativo, as organizações locais de sindicatos e cooperativas e outras entidades ou iniciativas semelhantes possam desencadear, incentivar e reforçar tais redes" (p.9). Exemplos concretos não faltam dessas ações. O autor citado destaca o SICREDI, no Rio Grande do Sul e em outros estados, com seus 396 postos espalhados e que em mais de 60 municípios constitui a única agência bancária existente. "Por outro lado, o mesmo cooperativismo de crédito, nas suas modalidades de crédito rural e de economia e crédito mútuo e de crédito médico, num total de 1066 cooperativas em dezembro de 2002, tem espalhados 2137 postos de atendimentos em um país com 5507 municípios, representando 38,08\% dos municípios brasileiros" (ibidem, p.10). A fortaleza do movimento cooperativista em conjunto com outras iniciativas da sociedade de civil organizada, assim, irradiaria a "cultura da mutualidade" para além do próprio âmbito da cooperativa e em direção comunitária mais ampla.

Entre as vantagens econômicas, sociais, educativas e éticas das cooperativas e das ações do cooperativismo, Schneider (2002) destaca: (a) o fomento da poupança e da qualidade dos produtos e serviços; (b) as rendas maiores e regulares nas cooperativas de produção, de produtores e de prestação de serviços; (c) a elevação geral do nível de vida dos associados e das comunidades nas quais as cooperativas estão inseridas; (d) a solução 
contra a intermediação exploradora, os monopólios e outras formas de especulação; (e) a instrumentalização da distribuição social e regional de renda; (f) a regulação de preços no mercado, no caso do consumo, em prol de preços descendentes e, para os produtores, (...) a obtenção de melhores preços; (g) a promoção da humanização da economia; (h) a democratização econômica e, também, política. Inclusive no sentido da participação política dos cooperativados e das comunidades beneficiadas; (i) a difusão da consciência e do trabalho solidário; ( $\mathrm{j}$ ) a preservação da autonomia, da dignidade pessoal e da liberdade individual nos contextos das ações comuns e $(\mathrm{k})$ o incentivo à participação ética e promoção da educação popular, tendo assim um sentido político-pedagógico. (p.32-38)

Por sua vez, a III Plenária Nacional do Fórum Brasileiro de Economia Solidária (FBES), reunida em junho de 2003, respeitando a diversidade das suas práticas, elencou os seguintes pontos de identidade convergente: "a valorização social do trabalho humano, a satisfação plena das necessidades de todos como eixo da criatividade tecnológica e da atividade econômica, o reconhecimento do lugar fundamental da mulher e do feminino numa economia fundada na solidariedade, a busca de uma relação de intercâmbio respeitoso com a natureza, e os valores da cooperação e da solidariedade". Para seus formuladores, "a Economia Solidária constitui o fundamento de uma globalização humanizadora, de um desenvolvimento sustentável, socialmente justo e voltado para a satisfação racional das necessidades de cada um de todos os cidadãos da Terra" (ver www.fbes.org.br).

Os defensores do cooperativismo e da economia solidária ainda reiteram as possibilidades concretas de juntarem esforços com outras organizações da sociedade civil na busca do desenvolvimento local e sustentável, da distribuição eqüitativa dos bens, dos serviços e da renda.

\section{I.3 - Sociedade civil, protagonismo e identidade}

Depois de tentarmos compreender, ainda que brevemente, as mudanças no mundo do trabalho no cenário da globalização hegemônica e do seu braço neoliberal, e as possibilidades alternativas criadas pelo cooperativismo e pela economia solidária em meio ao que Boaventura de Sousa Santos chama de cosmopolitismo da "globalização-de-baixopara-cima", precisamos compreender os novos protagonistas da sociedade civil brasileira. Para isso, necessitamos perguntar: (a) Quem são esses protagonistas e quais alterações caracterizam a sociedade civil no tempo presente? (b) Quais são seus sentidos de ação, seus novos significados políticos e seus processos identitários?

Segundo Maria da Glória Gohn (2005), atualmente são protagonistas da sociedade civil:

As ONGs, os movimentos sociais, as comissões, grupos e entidades de direitos humanos e de defesa dos excluídos por causas econômicas, de gênero, raça, etnia, religião, portadores de necessidades físicas especiais; associações e cooperativas de autogestão de redes de economia popular solidária; inúmeras associações e entidades com perfis variados do Terceiro Setor; fóruns locais, regionais, nacionais e internacionais de debates e lutas para o encaminhamento de questões sociais; entidades ambientalistas e de defesa do patrimônio histórico e arquitetônico; redes comunitárias de bairros, conselhos populares e setores organizados que atuam nos conselhos institucionalizados das áreas sociais. Mas a sociedade civil incluiu também algumas empresas e fundações que atuam segundo critérios de responsabilidade social. (p.107) 
Com as redefinições neoliberais dos papéis desempenhados pelo Estado - que implicou transferências de responsabilidades para a sociedade civil por meio de parcerias -, com as mudanças da economia formal, no mundo do trabalho e a expansão da informalidade, as ONGs se fortaleceram, os sindicatos se enfraqueceram e os movimentos sociais populares se tornaram menos reivindicativos e mais propositivos. As organizações do Terceiro Setor intensificaram suas atuações juntos aos grupos considerados mais vulneráveis, com projetos e objetivação de resultados imediatos. Constata-se, neste sentido, uma nova identidade $e^{i i}$ cada vez mais heterogênea e fragmentada, também identificada por Antunes (1995 e 1999). Ainda conforme Gohn, antes citada, essa identidade alicerçou-se em três caminhos: (1) o econômico, trabalhando com "os vulneráveis, os miseráveis, os eu estavam em situação de risco e, não, todos os pobres"; (2) o fracionamento, ou seja, os vulneráveis foram divididos e inseridos em "programas elaborados segundo critérios de raça, etnia, gênero, idade etc."; (3) o protagonismo social, pautado por "uma nova forma de ativismo social... não mais para protestar, mas para fazer, laborar, atuar junto às camadas desfavorecidas" (p.109). Assim, "surgiram comunidades organizadas em projetos sociais com crianças, jovens, adolescentes, mulheres; cooperativas de todos os tipos de produtos e serviços, todos atuando segundo a lógica do desenvolvimento sustentável, nos marcos de uma nova economia social, criando o capital social" (ibidem). Não podemos esquecer os movimentos dos sem-terra, onde se destaca o MST com suas amplas reivindicações que vão da luta pela terra à economia, da educação à saúde. Em termos identitários, verificaram-se deslocamentos, redefinições e novas formas de ação e de pensamento social. Fragmentação e perca de identidade misturaram-se com redefinições, alterações de condutas e projetos. Alguns se inseriram nas possibilidades contra-hegemônicas da globalização, alardeando seus protestos contra a ordem econômica imposta e/ou se organizando pela via dos grandes eventos internacionais (como o Fórum Social Mundial e seus desdobramentos) e usando a Internet como poderosa aliada na disseminação de idéias e formas organizativas.

Neste amplo contexto, é fundamental notar que os movimentos sociais readquiriram a importância estratégica e a visibilidade que haviam declinado. Temos desde organizações que pugnam pela integração dos grupos vulneráveis nas políticas sociais compensatórias, até organizações que visam à profunda transformação social e usam fóruns e redes para lutar pela mudança do modelo atual de desenvolvimento excludente. Estas têm como referência um "novo modelo civilizatório em que a cidadania, a ética, a justiça e a igualdade social sejam imperativas, prioritárias e inegociáveis" (ibidem, p.113). E, para este novo modelo, torna-se fundamental compreender "a educação que está se dando no interior dos movimentos sociais, uma educação que a gente 'não está vendo nem pegando'. É exatamente essa educação nova, que ainda não é reconhecida como tal, que será sistematizada quando a sociedade mudar", como já afirmava Paulo Freire (1982, p.126) no início da década de 1980.

\section{Parte II - Globalização, precarização do trabalho e da identidade docente}

\section{II.1 - Precarização do trabalho e identidade docente}

As reformas econômicas e educacionais engendradas globalmente e no Brasil, indicadas anteriormente, consolidaram antigas e impregnaram novas marcas na classe-quevive-do-trabalho e nos trabalhadores da educação, em particular. O trabalho precarizado, o 
subemprego, os trabalhos temporários, o desemprego, os salários aviltantes, as condições subalternas e desqualificadas de trabalho, assim como a corrida pela qualificação exigida pelo mercado, permeiam a profissão docente na atualidade. Somadas a essas condições multiplicam-se as doenças físicas e psíquicas, a alienação do trabalho, as faltas constantes nas aulas. A violência diversificada já compõe o cotidiano de grande parte das escolas brasileiras e, em muitas delas, as grades, o medo e os sintomas de uma guerra social não declarada assustam os mais otimistas. Como ficam o trabalho e a identidade docente neste contexto?

A observação mais notória é a de que nas duas últimas décadas as mudanças produtivas disseminadas pela globalização e pelo neoliberalismo têm trazido novas demandas à escola, têm mudado a gestão, o currículo e a organização do trabalho escolar e, como não poderia deixar de ser, têm alterado o trabalho docente. Talvez possamos identificar essas mudanças com um conjunto de palavras definidoras que marcam as atuais tendências do trabalho dos/as professores/as: flexibilização, precarização, desprofissionalização, proletarização, desgaste, insatisfação, insegurança, desamparo e doenças funcionais.

Já sabemos de onde vêm essas novas direções e quais são as motivações que impactam o trabalho escolar e dos trabalhadores da educação. No entanto, uma visão mais aproximada poderia ser sintetizada pelas propostas ratificadas na Conferência Mundial sobre Educação para Todos (Jomtien, 1990), entre as quais a "educação para a eqüidade social" passou a ser tese central para a educação básica.

A educação como principal meio de distribuição de renda e garantia de mobilidade social será combinada à noção de que o acesso, hoje, à cultura escrita, letrada e informatizada é inevitável e constitui-se no único meio de ingressar ou permanecer no mercado de trabalho ou, ainda, sobreviver na chamada sociedade do terceiro milênio (Delors, 1998). Observa-se, então, um duplo enfoque nas reformas educacionais que se implantam nesse período na América Latina: a educação dirigida à formação para o trabalho e a educação orientada para a gestão ou disciplina da pobreza. A fórmula para se expandirem os sistemas de ensino de países populosos e com grandes níveis de desigualdade social será buscada por meio de estratégias de gestão e financiamento, que vão desde a focalização das políticas públicas educacionais ao apelo ao voluntarismo e ao comunitarismo. (Oliveira, 2004, p.1130, grifos nossos)

Ademais,

Tais reformas serão marcadas pela padronização e massificação de certos processos administrativos e pedagógicos, sob o argumento da organização sistêmica, da garantia da suposta universalidade, possibilitando baixar custos ou redefinir gastos e permitir o controle central das políticas implementadas. (...) Tais estratégias possibilitam arranjos locais como a complementação orçamentária com recursos da própria comunidade assistida e de parcerias. A eqüidade far-se-ia presente, sobretudo nas políticas de financiamento, a partir da definição de custos mínimos assegurados para todos. (ibidem, grifos nossos)

Importante observar que, apesar das adoções do "construtivismo pedagógico", da continuidade do escolanovismo como referência, da ênfase na aprendizagem (aprender a aprender, a fazer, a conviver e a ser, Delors/UNESCO), a responsabilização dos professores/as como agentes centrais do sucesso/fracasso dos novos parâmetros 
curriculares e a sobrecarga das "novas exigências" da globalização educacional têm marcado a tônica principal. Assim,

O professor, diante das variadas funções que a escola pública assume, tem de responder a exigências que estão além de sua formação. Muitas vezes esses profissionais são obrigados a desempenhar funções de agente público, assistente social, enfermeiro, psicólogo, entre outras. Tais exigências contribuem para um sentimento de desprofissionalização, de perda de identidade profissional, da constatação de que ensinar às vezes não é o mais importante. Essa situação é ainda mais reforçada pelas estratégias de gestão já mencionadas, que apelam ao comunitarismo e voluntariado, na promoção de uma educação para todos. Nesse contexto é que se identifica um processo de desqualificação e desvalorização sofrido pelos professores. As reformas em curso tendem a retirar deles a autonomia, entendida como condição de participar da concepção $e$ organização de seu trabalho. (ibidem, p.1131, grifos nossos)

Conforme o trabalho de Rodrigues (Sociologia das profissões, 2002), a expansão da escolarização e as exigências de "clientes" escolares com maior participação e discernimento, devido aos avanços da informação e da própria educação, trariam como resultante a crescente perda de poder, de autonomia e de autoridade por parte dos profissionais da educação. Podemos argumentar que as alterações da identidade profissional desses trabalhadores é parte dessas conseqüências. Somam-se a esses fatores alguns movimentos "bem intencionados" que, certamente, abalam a profissão (ou a falta de profissionalismo?). A tão decantada participação da comunidade na escola (pais, "amigos", sociedade em geral) passa a idéia de que a educação é feita por todos e, assim, não seria trabalho de especialista/profissional. Por outro ângulo, o fato de que o conhecimento se busca no computador, na "sociedade da informação", pode adicionar um sentimento de perda da importância do/a professor/a. A histórica falta de regulamentação da profissão, coadjuvada pela expressiva quantidade de professores/as leigos/as (sem formação) e de professores/as que atuam em áreas que não têm formação, agrava o quadro. Considerando, ainda, as precárias condições de trabalho da maioria das escolas brasileiras e os níveis salariais absolutamente insatisfatórios - que obriga parte significativa dos/as professores/as à tripla jornada diária com um grande número de aulas semanais para garantir a sua sobrevivência -, teremos um quadro da pressão que incide sobre esse trabalhador e à sua identidade profissional. Como complicador, as novas exigências dos conteúdos e metodologias (transversalidade dos currículos, interdisciplinaridade, novas formas de avaliação etc.) sem a devida formação (ou nova formação), tendem a colocá-lo em um "beco sem saída", identificado pelo medo do novo e a insegurança dos que não sabem e têm que ensinar. A nova organização escolar e o novo discurso não investiram o suficiente para formar os agentes que, na prática, continuam a ser os principais responsáveis pelo sucesso educacional.

Podemos considerar que assim como o trabalho em geral, também o trabalho docente tem sofrido relativa precarização nos aspectos concernentes às relações de emprego. $\mathrm{O}$ aumento dos contratos temporários nas redes públicas de ensino, chegando em alguns estados ao número correspondente ao de trabalhadores efetivos, o arrocho salarial, o não respeito a um piso salarial nacional, a inadequação ou mesmo ausência, em alguns casos, de planos de cargos e salários, a perda de garantias trabalhistas e previdenciárias oriunda dos processos de reforma 
do Aparelho de Estado têm tornado cada vez mais agudo o quadro de instabilidade e precariedade do emprego no magistério público. (Oliveira, 2004, p.1141)

No caso brasileiro, há de se enfatizar, ainda, as disparidades regionais e a heterogeneidade do sistema escolar quando contemplamos os mais de 5000 municípios. Se compararmos as regiões e os municípios onde as redes públicas são muitas vezes ainda mais precárias quanto às condições de trabalho e de salário, teremos um quadro ainda mais perverso. E, embora não possamos estender as observações feitas a todos/as professores/as brasileiros, podemos representar a identidade da grande maioria dos profissionais da educação e do ensino.

Destarte, podemos dizer que os/as docentes brasileiros/as, em geral, cujas exceções servem para confirmar a regra generalizada, vivenciam a precarização do trabalho e foram perdendo ao longo do tempo suas posições sociais como integrantes das camadas médias, suas condições de trabalho adequadas e seus salários. Muitos se agarraram no suposto último tentáculo profissional: a detenção e a transmissão de um saber ao qual estaria ligado o seu último pedaço de poder. Na medida do avanço da "sociedade da informação" e do uso das Tecnologias da Informação e Comunicação (TICs), da participação de vários segmentos não-escolares nos direcionamentos da escola dando a impressão que esta não precisa de profissionais especializados e mesmo que pode/deve funcionar "apesar deles", somados à flexibilização profissional, à proletarização, ao mesmo tempo em que se multiplicaram outras responsabilidades não diretamente ligadas ao ensino, os docentes viram seu "último poder" (de detentor e transmissor do saber) também desvanecer. Como agravante, multiplicaram-se as situações que exigem desempenho, performance e eficácia de um trabalhador combalido em sua auto-estima, inseguro e desamparado.

Todas essas constatações parecem fazer parte de um mecanismo maior que pela via da globalização educacional impactou as reformas educacionais brasileiras (nos diferentes graus de ensino) a partir dos anos 1990 e que podem ser resumidas nas conclusões de alguns dos principais pesquisadores registradas em outro texto (Scocuglia, 2008) ${ }^{\mathrm{iii}}$. Segundo essas constatações, uma das expressões máximas dessas reformas tem se verificado no processo de municipalização do ensino fundamental, da educação infantil e de jovens e adultos, nas quais o discurso central é o da descentralização, enquanto instrumentalização da modernização gerencial da gestão pública adotada. Trata-se, no entanto, segundo Janete Lins Azevedo (2002), muito mais de uma prática desconcentradora na qual o local é considerado uma unidade adminstrativa de execução das determinações do poder central que, por sua vez, são submissas aos mecanismos internacionais e às prescrições das agências centrais da globalização hegemônica. Neste sentido, a descentralização que sempre figurou como reivindicação de grupos progressistas é inteiramente redefinida, tendo como características: (a) a descentralização política (com a transferência de recursos e atribuições); (b) a descentralização administrativa (por delegação de autoridade aos "gerentes" educacionais); (c) a definição de objetivos a serem mensurados e avaliados pelo poder central; (d) o controle dos resultados e (e) o atendimento do cidadão-cliente. Assim, devem-se condicionar as gestões escolares e os processos de ensino-aprendizagem ao modelo gerencial conforme as prescrições das agências internacionais de cooperação e financiamento para garantir a qualidade dos serviços e a relação otimizada entre sua qualidade e seus custos (Bresser Pereira, MARE, 1995, apud Azevedo, 2002). Conforme a autora, 
O processo de municipalização, tal qual o estamos assistindo, não pode, pois, ser analisado sem que tenhamos presente o fato de que se baseia numa lógica economicista-instrumental e que se articula com um movimento mais amplo: o projeto de sociedade em implementação no Brasil, que se alinha e se subordina aos reordenamentos do processo de acumulação capitalista, firmados nas últimas décadas do século XX (que) implicaram novas formas de definição e de articulação entre os espaços local, nacional e global, com profundas repercussões para os padrões societais, para as políticas sociais e, portanto, para a educação que vem se reformando em escala planetária. (Azevedo, 2002, p. 55)

Com efeito, nessa lógica destacam-se as práticas da gestão marcadas, por exemplo, pela adminstração de projetos e pelos princípios da competitividade.

No ensino médio, as reformas são objetivadas no sentido do "exercício a cidadania e da organização o trabalho, impostos pela nova geografia política do planeta, pela globalização econômica e pela revolução tecnológica" (MEC/SEMTEC, 2002). Tais objetivos teriam como base o desenvolvimento das competências e habilidades necessárias à adaptação e à integração sociais e ao novo mundo do trabalho. No entanto, os resultados dessas reformas têm evidenciado um crescente descrédito em relação às possibilidades de ascensão social e de inserção no mundo do trabalho por parte dos estudantes e pode-se admitir que a violência nas escolas de ensino médio constitui uma das respostas à essa frustração. As camadas médias e altas da sociedade cada vez mais se afastam da escolarização pública que fica reservada ao "excluídos do interior" (Bordieu \& Champagne, 1999) do sistema. Assim, ganha corpo a denúncia de Silva Jr. (2002), segundo a qual "radicalizando as desigualdades, as políticas públicas para o ensino médio estão formando o cidadão do século XXI, como propõe o Relatório de Delors: o cidadão produtivo: útil, mudo, competitivo e solitário" (p. 222).

Em outro grau do sistema em reformas, o documento La ensenãnza superior: las leciones derivadas de la experiencia (1995), do Banco Mundial, parametriza: (1) a "privatização desse nível de ensino, sobretudo em países como o Brasil, que não conseguiram estabelecer políticas de expansão das oportunidades educacionais"; (2) o "estímulo à implementação de novas formas de regulação e gestão das instituições estatais (...) que permitam a busca de novas fontes de recursos junto à iniciativa privada"; (3) a "aplicação de recursos públicos nas instituições privadas"; (4) a "eliminação de gastos com políticas compensatórias (moradia, alimentação)" e (5) a "diversificação do ensino superior, por meio da incrementação de instituições não-universitárias" (Dourado, 2002, p. 238). Para a instauração dessas políticas a Lei de Diretrizes e Bases da Educação Nacional (1996) estabeleceu, entre os seus princípios contraditórios, a descentralização/flexibilização e a controle exercido pelas avaliações padrão. Tal sistema avaliativo implicou: um processo de "economização da educação"; "mudanças significativas na gestão universitária, na produção do trabalho acadêmico e na formação profissional"; maior "poder de controle do Estado" (Catani, Dourado e Oliveira, 2002).

\section{II.2 - Reinventar a prática e a identidade docentes}

O que fazer diante deste quadro? Quais são as saídas? Se a globalização hegemônica e o neoliberalismo marcaram o quadro do "Estado mínimo" e a "mercantilização dos serviços educacionais", a globalização contra-hegemônica, a organização coletiva, as 
"redes" de professores que se utilizam da Internet para se comunicar e as outras tentativas e saídas podem reverter os vetores apresentados? Há possibilidades e esperanças? O sindicalismo tem oferecido respostas? Estamos em um "beco sem saída" ou emaranhados em encruzilhadas e em labirintos? Enfim, a reconstrução positiva de uma identidade pessoal/profissional fragmentada e em crise é possível para os trabalhadores da educação em tempos neoliberais e globalizados?

António Nóvoa (1999) ajuda-nos a raciocinar sobre essas e outras questões. Em seu artigo "Professores na virada do milênio: do excesso do discurso à pobreza das práticas" focaliza quatro questões principais, a saber: as políticas educativas, a formação dos professores, as práticas pedagógicas e o associativismo docente. Sobre as políticas educativas, Nóvoa chama a atenção sobre as ambiguidades manifestas pela sociedade sobre as escolas. Transfere-se para as escolas e para a responsabilidade dos professores/as tarefas que as comunidades deveriam desempenhar e parece que tudo tem que ser resolvido pela escola inclusive a restauração da lógica da autoridade perdida socialmente. Competir num mundo comandado pelo mercado também se deve aprender na escola. Neste caminho, autoridade e competição permeariam a escola pragmática "do mercado" e a democracia participativa seria muito mais uma retórica do que uma prática a ser conseguida. Mas,

Os professores sabem que não é assim. E que a democracia começa no respeito pelas crianças e pelos seus percursos. E sabem que são eles que têm de defender a possibilidade destes percursos, por vezes contra as famílias ou contra as comunidades locais. Mas, para tal, é preciso que exista um resgate social da profissão docente e a definição de políticas educativas coerentes. Os professores têm de redescobrir uma identidade colectiva, que lhes permita cumprir o seu papel na formação das crianças e dos jovens. Os tempos de hoje são mais complexos do que os tempos passados. E mais difíceis. Mas grande parte das crenças fundadoras da profissão docente continua actual. A começar por esse sentimento de que nos compete cuidar das crianças e do seu futuro. Para que isso seja possível, é fundamental que os professores ocupem um espaço mais dinâmico (e menos defensivo) nas mudanças em curso. (Nóvoa, 1999, p.14, grifos nossos)

Para que isso aconteça, a formação permanente e qualitativa dos/as professores/as precisa deixar de ser retórica e se tornar efetiva. Criticando receitas academicistas, a exemplo do "professor reflexivo", Nóvoa complementa:

Pela minha parte, gostaria de perceber como é que os professores reflectiam antes de os investigadores terem decidido que eles eram "profissionais reflexivos". E encontrar processos que valorizem a sistematização dos saberes próprios, a capacidade para transformar a experiência em conhecimento e a formalização de um saber profissional de referência. As abordagens autobiográficas (não apenas num sentido pessoal, mas geracional), as práticas de escrita pessoal e colectiva, o desenvolvimento de competências "dramáticas" e relacionais ou o estímulo a uma atitude de investigação deveriam fazer parte de uma concepção abrangente de formação de professores. É verdade que não faltam programas em que estas dimensões estão contempladas. Mas a questão essencial não é organizar mais uns "cursos" ou atribuir mais uns "créditos de formação". O que faz falta é integrar estas dimensões no quotidiano da profissão docente, fazendo com que elas sejam parte 
essencial da definição de cada um como professor/a. (ibidem, p.15)

Com efeito, inevitavelmente as premissas e as atividades da formação profissional docente estão em estreita combinação com as práticas pedagógicas desenvolvidas. $\mathrm{O}$ auxílio das Tecnologias da Informação e da Comunicação (TICs) tem secundarizado a atuação dos/as professores/as e em muitos casos, já citados, tem até eliminado a sua atuação como se já fossem descartáveis. O fato de recorrerem-se às TICs não significa a diminuição/eliminação dos papéis docentes, mas, ao contrário, significam novos recursos de aprimoramento desses papéis e novas possibilidades de trabalho. Por outro ângulo, vivemos a época das incertezas paradigmáticas da quais as práticas pedagógicas fazem parte e a necessidade da vivência docente (só possível para quem a exerce) torna-se ainda mais fundamental. Ou seja, entre tantas teorias, conceitos, paradigmas emergentes e em declínio, entre tantas encruzilhadas teóricas, a reflexão sobre a prática para melhorá-la parece ser o caminho mais prudente. As observações de Nóvoa são esclarecedoras e nos remetem à questão central da identidade docente:

Um elemento essencial deste debate é a afirmação de que as zonas indeterminadas da prática se encontram no cerne do exercício profissional docente. Tal facto leva-nos a conceder uma nova atenção à idéia de deliberação. O momento em que o professor julga e decide, a partir da análise de uma situação singular e com base nas suas convicções pessoais e nas suas discussões com os colegas, transforma-se, assim, numa dimensão central do processo identitário. Um outro elemento, que tem sido pouco explicitado, diz respeito ao horizonte ético do trabalho docente. É uma reflexão inevitável, num tempo marcado por tantos conflitos e dilemas. Os professores não podem refugiar-se numa atitude "defensiva" e têm de estar preparados para enfrentar as interpelações dos seus alunos. A definição da consciência e da responsabilidade profissional não se esgota no acto técnico de ensinar e prolonga-se no acto formativo de educar. A concepção de práticas pedagógicas que respondam a estas preocupações contém, actualmente, uma dimensão organizacional e, por isso, é tão importante reequacionar o papel da escola como espaço de referência da profissão docente. (ibidem, p.17)

O outro ponto enfatizado por Nóvoa, e que complementa a discussão anterior, referese ao associativismo docente. Embora na teoria as idéias de cooperação, coletividade, equipes de trabalho, inter/transdisciplinaridade, formação compartilhada e outras sejam reiteradamente disseminadas, na prática temos o predomínio do individualismo e a fraqueza desmobilizadora das associações e dos sindicatos dos trabalhadores docentes. Para ele, antes de tudo, torna-se necessário "inscrever a dimensão coletiva no habitus profissional dos professores". Visualizando a construção de uma "competência coletiva" (Guy Le Boterf, apud Nóvoa, 1999, p.18) destaca a importância do aparecimento de "um actor colectivo, portador de uma memória e de representações comuns, que cria linguagens próprias, rotinas partilhadas de acção, espaços de cooperação e dinâmicas de co-formação participada. É uma mudança decisiva para a profissão docente". Claro está que o apelo do sindicato e da associação docente é insubstituível. No entanto, em tempos de enfraquecimento da postura política e da própria imagem sindicalista construída por muitos anos com movimentos grevistas parece fadada ao declínio (na última década, as longas 
greves das Universidades federais brasileiras demonstram essa premissa com nitidez) e impõe a necessidade de novas práticas organizativas e de ações políticas.

Concordamos com Nóvoa quando argumenta que, para as propostas acima expostas se efetivem, "é preciso que os professores sejam capazes de reflectirem sobre a sua própria profissão, encontrando modelos de formação e de trabalho que lhes permitam não só afirmar a importância dos aspectos pessoais e organizacionais na vida docente, mas também consolidar as dimensões colectivas da profissão" (ibidem, p.19). E, não há dúvida que essa é uma tarefa imediata e, também, permanente.

\title{
Considerações finais
}

Para a globalização hegemônica e o neoliberalismo, os indivíduos devem ter uma identidade coletiva guiada pela competição e pela sua inserção no mercado. As diversidades e as diferenças individuais devem ser respeitadas desde que não interfiram na identidade coletiva competitiva e mercadológica. E, certamente, a educação deve contribuir para forjar esse indivíduo-trabalhador identificado com essas matrizes.

No entanto, sabemos que a identidade é constituída de características individuais e coletivas que definem os homens e as mulheres como seres relacionais que estão no mundo e com o mundo. Por isso mesmo, o conhecimento e a consciência crítica que um indivíduo tem de si mesmo e de sua relação com os outros é componente essencial das identidades. Por outro prisma, como processo humano de ser mais, de conhecimento e de consciência, a educação desempenha o papel de gerar cultura e identidades. Ademais, as identidades são construídas historicamente, ou seja, em espaços e tempos em movimento. E como possibilidade subjetiva de serem reconstruídas. Para Freire (1993),

\begin{abstract}
A importância do papel interferente da subjetividade na história coloca, de modo especial, a importância do papel da educação. A prática política que se funda na compreensão mecanicista da história, redutora do futuro a algo inexorável, castra as mulheres e os homens na sua capacidade de decidir, de optar, mas não tem força suficiente para mudar a natureza mesma da história. (...) Como processo de conhecimento, formação política, capacitação científica e técnica, a educação é prática indispensável aos seres humanos e deles específica na História como movimento, como luta. A história como possibilidade não prescinde da controvérsia, dos conflitos que, em si mesmos, já engendrariam a necessidade da educação. (p.14)
\end{abstract}

Nos caminhos da história como movimento, como luta e como possibilidade da transformação, apontados por Freire, poderemos vislumbrar as tentativas de reinventar as práticas educacionais e, nelas, as identidades dos trabalhadores da educação, professores e professoras. Essa reinvenção certamente passaria por revalorização profissional marcada pelo "trabalho como princípio educativo" e como espaço de mobilização ética e política. Passaria também pela reinvenção das associações docentes que

Deveriam lutar muito para levar um discurso diferente, eminentemente político, aos trabalhadores do ensino, sem deixar de apoiá-los em suas reivindicações de ordem salarial, que são absolutamente necessárias, porque é a partir daí que o sujeito, com sua sobrevivência, pode pensar

Revista HISTEDBR On-line, Campinas, número especial, p. 175-190,ago.2010 - ISSN: 1676-2584 187 
(...). Tentar um trabalho político de capacitação dos professores e o desvelamento do momento histórico em que os professores estão lutando, trabalhando, bem ou mal, a sua responsabilidade diante de uma geração inteira, com quem trabalham, o seu poder, na medida em que organizam. (Freire, 1982, p.43)

Uma nova identidade docente também demandaria o entendimento da ação do educador-educando como intelectual, problematizador e organizador, cujo papel "não é o de depositar na classe trabalhadora, que também é intelectual, os conteúdos da teoria revolucionária, mas o de, aprendendo com ela, ensinar a ela" (1985b:68). Com essa inspiração gramsciana, Freire enfatiza:

\begin{abstract}
Os intelectuais que aderem a esse sonho têm que selá-lo na passagem que devem realizar ao universo do povo. No fundo, têm de viver com ele uma comunhão em que, sem dúvida, terão muito o que ensinar se, porém, com humildade e não por tática, apreenderem o renascer como um "intelectual-ficando-novo". Quanto mais o intelectual se exponha a esse aprendizado, tanto mais percebe que o ponto de partida para a transformação da sociedade não está própria e exclusivamente no seu sonho, não está na sua compreensão da história, mas (também) na compreensão das classes populares. (1985, p.68)
\end{abstract}

Necessário enfatizar que a identidade do trabalhador docente não se refaz em si, mas na própria reinvenção da educação impactada pela globalização excludente e pelo neoliberalismo. Neste sentido, uma educação contribuinte para a globalização contrahegemônica precisa se nutrir, necessariamente, de uma pedagogia da pergunta, da indignação e da ousadia para combater a pedagogia do fatalismo e do medo. Precisa ser um caminho de conquista da autonomia para que seus protagonistas persigam a utopia, o inédito que é viável, enfim, a história como possibilidade do novo, da mudança. Para concretizar esta educação, Freire foi incisivo ao rechaçar a "pós-modernidade neoliberal" e defender a "pós-modernidade progressista e crítica" ressaltando sua politicidade e a defesa intransigente da democracia participativa. Apostou na possibilidade de concretização do que foi negado pela modernidade à classe-que-vive-do-trabalho e no rechaço do absolutismo da razão tecno-econômica e instrumental que atrofiou as possibilidades concretas da hominização. Mas apostou, também, nas tendências pós-modernas que investem no respeito às diferenças, à diversidade, às questões de gênero e de etnia, dos direitos responsáveis por uma cidadania plena, planetária e multicultural para os que não tiveram (ou tiveram pouca) voz e vez e que continuam a se espalhar pelo mundo (Scocuglia, 2005a). Afinal, a educação lastreada na ação dialógica, na conquista da consciência crítica, na problematização do conhecimento e na pedagogia da esperança, da indignação e da autonomia, da ética e da justiça social pode vir a ser um vigoroso contraponto à precarização do trabalho e à dilaceraçao da identidade docente - próprias da globalização hegemônica. 


\section{Referências}

ANTUNES, R. (1995). Adeus ao trabalho? São Paulo: Cortez.

ANTUNES, R. (1999). Os sentidos do trabalho. São Paulo: Boitempo.

ANTUNES, R. e ALVES, G. (2004). As mutações no mundo do trabalho na era da mundialização do capital. IN: Revista Educação e Sociedade, vol.25, No. 87, p.335-351.

AZEVEDO, J. M. L. de. (2002). Implicações da nova lógica de ação do Estado para a educação municipal. IN: Revista Educação e Sociedade, vol.23, no. 80, p.49-71.

BORDIEU, P. e CHAMPAGNE, P. (1999). Os excluídos do interior IN: CATANI, A. e

NOGUEIRA (org.). Pierre Bourdieu - Escritos de educação. Petrópolis: Vozes, pp. 217227.

CATANI, A.; DOURADO, L.F.; OLIVEIRA, J.F. (2002). A política de avaliação da educação superior no Brasil em questão. IN: DIAS SOBRINHO, J.; RISTOFF, D.I. (org.). Avaliação democrática para uma universidade cidadã. Florianópolis: Insular, pp. 99-118.

DALE, R. (2004). Globalização e educação: demonstrando a existência de uma "cultura educacional mundial comum" ou localizando uma "agenda globalmente estruturada para a educação"? IN: Revista Educação e Sociedade. Campinas, vol. 25, nº. 87, p.423-460.

DELORS, J. (2000). Educação - um tesouro a descobrir. São Paulo: Cortez/UNESCO.

DOURADO, L. F. (2002). Reforma do Estado e as políticas para a educação superior no Brasil nos anos 90. Revista Educação e Sociedade, vol.23, No. 80, p.234-252.

FREIRE, P. (1980). Cartas à Guiné-Bissau. Rio de Janeiro: Paz e Terra. . (1984a). Pedagogia do oprimido. Rio de Janeiro: Paz e Terra.

. (1992). Pedagogia da esperança. São Paulo: Cortez.

. (1993). Política e educação. São Paulo: Cortez.

. (1996). Pedagogia da autonomia. São Paulo: Cortez.

FREIRE, P. et al. (1982). Sobre Educação (Vol. I). Rio de Janeiro: Paz e Terra.

FREIRE, P. et al. (1985). Por uma pedagogia da pergunta. Rio de Janeiro: Paz e Terra.

GOHN, M. da G. (2005). O protagonismo da sociedade civil - ONGs, movimentos sociais e redes solidárias. São Paulo: Cortez.

HIRATA, H. (2002). Nova divisão sexual do trabalho? São Paulo: Boitempo.

MEC/SEMTEC (2002). Parâmetros curriculares nacionais - ensino médio. Brasília: MEC.

MORAES, R. C. (2002). Reformas neoliberais e políticas públicas: hegemonia ideológica e redefinição das relações Estado-sociedade. Revista Educação e Sociedade, vol.23, No. 80, p.13-24.

MORIN, E. (1998). O Método - As idéias. Porto Alegre: Sulina.

NÓVOA, A. (1999). Os professores na virada do milênio: excesso de discursos à pobreza das práticas. IN: Revista Educação e Pesquisa, Vol. 25, No. 1, p.11-20.

OLIVEIRA, D. A. de (2004). A reestruturação do trabalho docente: precarização e flexibilização. IN: Revista Educação e Sociedade, vol.25, No. 89, p.1127-1144.

RODRIGUES, R. L. (2002). Sociologia das profissões. Oeiras: Portugal, Celta.

SANTOS, B. S. (2002). As tensões da modernidade. IN: www.dhnet.org.br/direitos/militantes/boaventura/boaventura4.html. 
SANTOS, $\quad$ B. $\quad$ S. $\quad$ (2004). Entrevista IN: www.ces.fe.uc.pt/BSS/documentos/JornalOGLOBNov2004.pdf.

SCHNEIDER, J. O. (2002). Globalização, desenvolvimento local sustentável $e$ cooperativismo. São Leopoldo: PPGCS/Unisinos (www.unisinos.br).

SCOCUGLIA, A. C. (2003). A história das idéias de Paulo Freire e a atual crise de paradigmas. João Pessoa: Editora Universitária - UFPB (4ª edição).

SCOCUGLIA. A. C. (2005a). Paulo Freire e a conscientização na transição pós-moderna, IN: Revista Educação, Sociedades e Culturas, No. 23, (Porto: Portugal).

SCOCUGLIA, A. C. (2005b). As reflexões curriculares de Paulo Freire. IN: Revista Lusófona de Educação, No. 6 (Lisboa: Portugal).

SCOCUGLIA, A. C. (2008). Globalizações, política educacional e pedagogia contrahegemônica, IN: Revista Iberoamericana de Educación, v. 48, p. 9-25 (Montividéo: Uruguai).

SILVA JUNIOR, J. dos R. (2002). Mudanças estruturais no capitalismo e a política educacional do Governo FHC: o caso do ensino médio. IN: Revista Educação e Sociedade, vol.23, no. 80 , p.201-233.

Sobre o autor: Docente do Programa de Pós-Graduação em Educação da Universidade Federal da Paraíba. Pesquisador do Conselho Nacional de Desenvolvimento Científico e Tecnológico (CNPq). Pesquisador visitante da Faculdade de Educação da UNICAMP. Pósdoutorado em Ciências da Educação pela Université de Lyon (França). E-mail: afonso.scocuglia@pq.cnpq.br.

\footnotetext{
i Para Boaventura de Sousa Santos (2002) globalização é um "conjunto de arenas de lutas trans-fronteiriças" (p. 6). As globalizações "de-cima-para-baixo" (hegemônicas) e "de-baixo-para-cima" (contra-hegêmonicas) comportam quatro formas de globalização: o localismo globalizado e o globalismo localizado seriam partes da primeira e o cosmopolitismo e o patrimônio comum da humanidade, da segunda. O localismo globalizado é o "processo pelo qual determinado fenômeno local é globalizado com sucesso" (ibidem, p. 5). O globalismo localizado é mostrado pelo "impacto específico de práticas e imperativos transnacionais nas condições locais, as quais são, por essa via, desestruturadas e reestruturadas de modo a responder a esses imperativos transnacionais" (ibidem, p. 5). No entanto, o cosmopolitismo e o patrimônio comum da humanidade não se caracterizam nem como globalismo localizado, nem como localismo globalizado. São formas antagônicas identificadas pelo autor como globalizações de-baixo-para-cima, ou seja, globalizações contra-hegemônicas.

ii "O conjunto de percepções e visões de mundo que um grupo constrói no processo de experiência histórica ao atuarem coletivamente, aliado às representações simbólicas que também constroem ou adotam, são a parte mais relevante da cultura política de um grupo porque é a partir destes elementos que o grupo constrói a sua identidade" (Gohn, 2005, p.34).

iii SCOCUGLIA, A. C. Globalizações, política educacional e pedagogia contra-hegemônica. Revista Iberoamericana de Educación, v. 48, p. 9-25, 2008.
}

Recebido dia 22/02/2010

Avaliado dia 20/03/2010 